\title{
"The Singularity is near!" Visions of Artificial Intelligence in Posthumanism and Transhumanism
}

\author{
Oliver Krüger* \\ University of Fribourg (Switzerland) \\ Received 16 January 2021 | Accepted 19 June 2021 | Published 20 July 2021
}

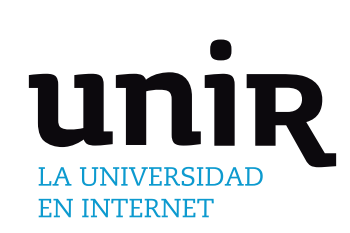

KEYWORDS

ABSTRACT

Over the past 20 years, the idea of singularity has become increasingly important to the technological visions of posthumanism and transhumanism. The article first introduces key posthumanist authors such as Marvin Minsky, Ray Kurzweil, Hans Moravec, and Frank Tipler. In the following, the concept of singularity is reviewed from a cultural studies perspective, first with regard to the cosmological singularity and then to the technological singularity. According to posthumanist thinkers the singularity is marked by the emergence of a superhuman computer intelligence that will solve all of humanity's problems. At the same time, it heralds the end of the human era. Most authors refer to the British mathematician Irving John Good's 1965 essay Speculations Concerning the First Ultraintelligent Machine as the originator of the idea of superintelligence. Individual elements of the singularity idea such as the impenetrable event horizon, the frontier and the ongoing acceleration of progress are contextualized historically and culturally.

Singularity, The. The Techno-Rapture. A black hole in the Extropian worldview whose gravity is so intense that no light can be shed on what lies beyond it.

$$
\text { Godling's Glossary [1] }
$$

\author{
Singularity, Artificial \\ Intelligence, \\ Ray Kurzweil, \\ Transhumanism, \\ Posthumanism.
}

\section{Post- And Transhumanism}

\begin{abstract}
MIDST the range of diverse thinkers advocating the overcoming - Lof humanity with the help of new technologies, many are often called transhumanists. Yet despite this increasingly frequent usage, I would still like to emphatically call for a differentiation between technological posthumanism and transhumanism. Not only does the term posthumanism, which is commonly used in art and cultural studies research, itself need to be clarified, but in fact noticeable differences can be found between the purposes, contents and origins of transhumanism and technological posthumanism.

Transhumanism primarily originated in California during the 1960s, and was decisively influenced by the visions of the futurist Fereidoun M. Esfandiary (FM-2030), by the commitment of Timothy Leary, the pioneer of the psychedelic movement, and by the cryonics expert Robert Ettinger. In the late 1980s this movement gave rise to the "Extropians" around Max More and, as European involvement increased, the World Transhumanist Association founded by Nick Bostrom, David Pearce and Anders Sandberg in 1998.
\end{abstract}

Technological posthumanism, on the other hand, unites a number of authors who have been propagating the replacement of humans by artificial intelligences since the mid-1980s. Its main four proponents, Hans Moravec, Frank Tipler, Marvin Minsky, and Ray Kurzweil, argue on the basis of cybernetic theory. Before the early 2000s these authors

${ }^{*}$ Corresponding author.

E-mail addresses: oliver.krueger@unifr.ch did not refer to the transhumanist movement and its themes in any way.

The second argument for a separation between post- and transhumanism is based on the different emphases in terms of content. Transhumanists deal practically with the issues of prolonging life and enhancement of mental performance, such as through the use of smart drugs, life-prolonging diets, advances in prosthetic technology, the potential for a renewed form of eugenics, or even the prospects of cryonics, while these applications are rarely mentioned in posthumanist writings.

Whereas in transhumanism the subject of development is humankind and what becomes of human beings with the help of technological upgrades and enhancements, in posthumanism robots and artificial intelligence are the future carriers of evolution and progress. In a virtual habitat the immortal existence of humans is a welcome side effect of the autonomous progress of artificially intelligent, post-human beings [19].

Now, who are the most significant thinkers in posthumanism? In his work Mind Children. The Future of Robot and Human Intelligence (1988) the roboticist Hans Moravec (born 1948) offered a vision of a post-biological and supernatural future for humankind. The preface reads like a preamble to posthumanism:

Engaged for billions of years in a relentless, spiraling arms race with one another, our genes have finally outsmarted themselves ... What awaits us is not oblivion but rather a future which, from our present vantage point, is best described by the words "postbiological" or even "supernatural". It is a world in which the human race has been swept away by the tide of cultural change, usurped by its own artificial progeny ... [2:1] 
Moravec's outstanding importance for posthumanist philosophy stems primarily from the fact that, he was the first scientist to formulate the technical possibilities of virtual immortality. Not as a science fiction author, but as a scientific visionary, Moravec portrays the technical procedure of this possible "transmigration" in precise detail as a scanning process of the brain. He thus develops his vision of humans as virtual simulation within a computer's memory, which will ensure his infinite existence while biological humanity slowly dies out [2:108-109].

Frank Jennings Tipler (born 1947) serves as professor for mathematical physics at Tulane University in New Orleans since 1981. His research mainly focuses on questions of general relativity, quantum theory, and cosmology related to his interest in the genesis and future development of the cosmos. Tipler became famous overnight with his 1994 book The Physics of Immortality. Modern Cosmology, God and the Resurrection of the Dead [3]. His position differs from that of other posthumanists in many regards - whether it be the cosmological emphasis, his euphoric images of virtual paradise, or his scientific inclusivism, which does not seek to overcome religion but to integrate it. According to Tipler, when the sun has burned all of fuel, in many billions of years, the only chance of survival for humans will become a virtual existence in gigantic computers. Tipler determines the goal of these cosmological developments as the Omega Point, which he identifies with God.

Marvin Minsky's (1927-2016) significance for posthumanism lies above all in the formulation of the cybernetic understanding of humankind, that means to define the human being as a particular type of information processing machines. Even in an inconspicuous textbook on computer science, he places the evolution of humans in relation to that of machines: "One has found himself sharing the world with a strange new species within a single generation: the computers and computer-like machines." [4:VII]. As a co-founder of the Massachusetts Institute of Technology's Media Lab, Minsky was the teacher and mentor of a number of the contemporary representatives of posthumanism and transhumanism such as Luc Steels, Eric Drexler, and Ray Kurzweil (born 1948)

The latter is certainly Marvin Minsky's most famous former student. He has founded no less than six companies in the information technology industry since graduating from MIT in 1970. Another career high point was certainly his 2012 appointment as a Director of Engineering at Google, where he focuses upon machine learning and language processing. In various interviews, Kurzweil always emphasizes that he is doing his utmost to achieve the singularity [5:1417].

His early work The Age of Intelligent Machines [6], published in 1990, was the best-selling book in computer science at the time. It provides a technical overview of the development of artificial intelligence. The book contains a short future scenario depicting potential consequences of the increasing use of machines in the working world, as well as some predictions for future leisure activities [6:401-416]. In 1990 Kurzweil's grandest prophecy was that a computer will have developed its own consciousness sometime between 2020 and 2070 [6:483]. However, Kurzweil wants to introduce the beginning of the end of humankind in his next book The Age of Spiritual Machines of 1999: According to him, by the year 2099 humans and machines will have merged, and humankind will have overcome its biological condition [7:277-280]. In his most radical work, The Singularity is Near. When Humans Transcend Biology of 2005, the prospect of salvation is accelerated by half a century to the year 2045, and Kurzweil promises a universal solution to all of humanity's problems [8]. Since the 1990s, Kurzweil has also been writing life-help books such as Fantastic Voyage: Live Long Enough to Live Forever [9] and Transcend: Nine Steps to Living Well Forever [10], both co-authored with Terry Grossman. In 2009, a documentary film about Kurzweil called Transcendent Man. The Life and Ideas of Ray Kurzweil was even screened [11].

\section{Singularities}

\section{A. Introduction}

The idea of the dawning of a new age of artificial intelligence has gained recognition far beyond the transhumanist milieu, primarily through Ray Kurzweil's book The Singularity is near: When Humans Transcend Biology (2005), numerous films and the founding of the Singularity University (SU) in 2008. Strictly speaking, the SU is not a university at all, it provides no curriculum, qualifying degrees and research facilities. It offers mainly marketing and network-working events for "disruptive" technological visions [12:63-76].

From a cultural studies perspective, this essay examines the cultural, religious, and philosophical elements of the singularity idea. This is not a scientific evaluation of the singularity or its technological feasibility. But with this analysis, cultural values and ideas can be uncovered that are also present in the further technological and political discourse on artificial intelligence. On closer inspection, the singularity proves to be a cultural rather than a technological idea.

Cultural studies scholars have previously attempted to arrange and analyze different approaches to singularity, yet these sometimes remain undifferentiated and polemical: Selmer and Alexander Bringsjord and Paul Bello see the entire singularity theory as a matter of faith without scientific basis [13]. The idea of singularity encompasses scientific concepts within mathematical function and system theory, geometry, solid-state physics, cosmology and cybernetics. The latter two areas particularly hold special significance for posthumanism. Even when merely scratching at the surface of the history of ideas, it quickly becomes clear that these two areas are closely interwoven. They contain numerous references, especially to the work of the Jesuit Pierre Teilhard de Chardin and his concept of the Omega Point. Alongside Reinhard Heil, I advocate considering each semantic layer individually, in order to elaborate the complex interdependencies between religion and science in this posthumanist utopia [14:44-46]. We will therefore examine the concept of singularity in three steps: The first two sections on cosmological and technological singularity will be followed by a cultural-historical contextualization of the concept itself.

\section{B. Black Holes and Cosmological Singularities}

The term singularity has been widely used in English since the 1980 s, as well as being creatively applied in literature and television series for popular audiences. According to the cosmologists Roger Penrose and Stephen Hawking, singularities (in the plural) denote the special conditions of space and time, such as those created by black holes. These are moments when matter or its precursors are concentrated at a single point and space and light become infinitely curved. The beginning of the universe - the Big Bang - was marked by a singularity [15]. The common understanding of singularity as well as the popular reception of the term in literature and television series usually refer to the fantastic space and time effects of black holes, to which the Penrose-Hawking singularity theorem is applied.

Together with cosmologist John D. Barrow, Frank Tipler steered the concept of cosmological singularities into philosophical realms encompassing questions of life and humanity's place in the universe. The two cosmologists reflect on the initial and final singularity within a closed universe model, i.e. the beginning and the end of the universe, which at this moment has no spatial-temporal extension. Here, Barrow and Tipler identify analogies with Teilhard de Chardin's work and equate the final singularity with the divine Omega Point. These 
two approaches can in fact be combined, since according to the Final Anthropic Principle, the end of the universe requires a final observer, which for Tipler is identical with God-Omega [16: 201-204, 470-471]. In his later works, Physics of Immortality of 1994 [3] and Physics of Christianity of 2007 [17], Tipler builds on these considerations and embeds the cosmological singularities in a theological framework, i.e. not only that God is the final goal of the universe, but that God is also its original cause, which was not yet subject to any physical laws.

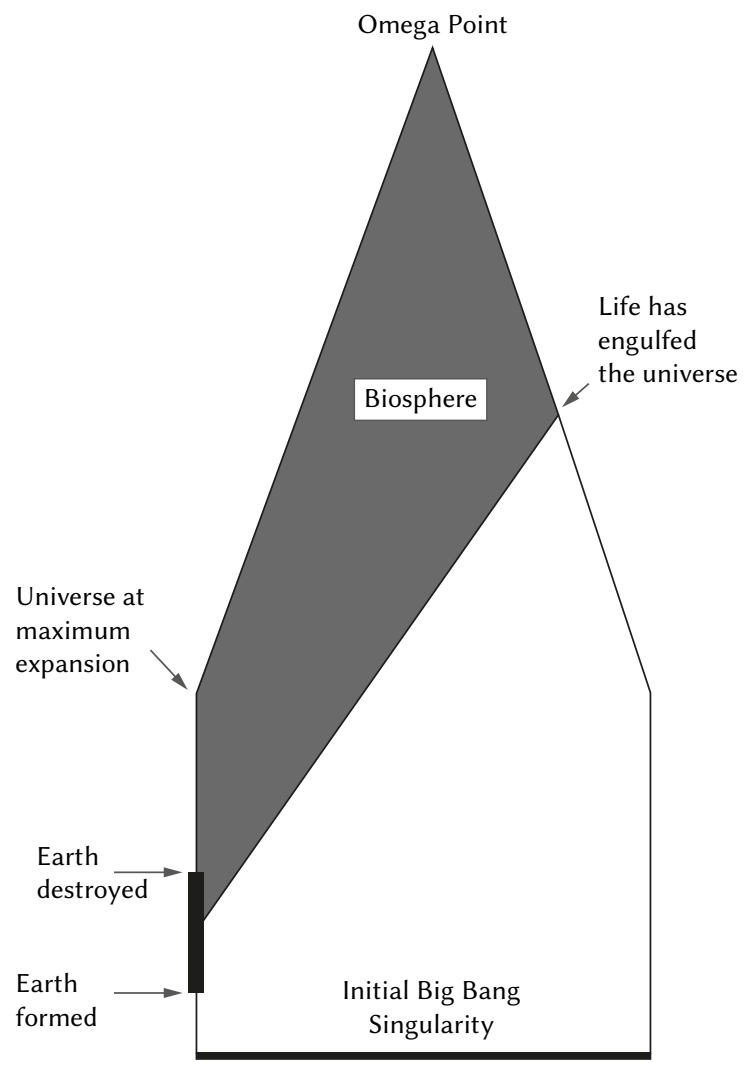

Fig 1. Penrose diagram of the future of life in the universe by Frank Tipler [3:145], Figure IV.9.

This image [Fig. 1] illustrates the temporal dimensions of Tipler's design. The earth's biosphere first begins to expand into space during our present age, in order to save the universe as it is colonized. In a 2013 interview with "Socrates" from Singularity Weblog, Tipler describes the properties of the final cosmological singularity as follows:

The singularity is outside the natural world, it is beyond the natural world, and it is transcendent to the natural world. So, approaching the singularity ... the amount of information, the amount of knowledge is approaching infinity as you are going into the final state. The processing rate is increasing to infinity. So, the total amount of information processing will be infinite [18].

Tipler takes an inclusive approach to the concept of technological singularity propagated by Kurzweil and other thinkers. He considers the technological singularity as merely a philosophical concept, while the cosmological singularity is presented as a proven mathematical theorem. According to Tipler, the technological singularity is only a small event in human history, caused by inevitable movement towards the cosmic singularity.

The cosmological singularity is determining, requiring the existence of the computer science singularity. And I agree with various people as Hans Moravec and Ray Kurzweil. And I think the singularity in computer science will occur in this century. I think we are very close. I think we already have the necessary hardware [18].

When he calls himself a "fundamentalist physicist", it finally becomes obvious that there is not a hint of irony in Tipler's statements. Under the conditions that the universe is closed and that humanity is the only intelligent life form in the cosmos (both of which are mathematically proven, according to Tipler), earthly life forms must find a new vehicle:

Namely, that eventually human meat, rational beings will be replaced by human downloads and our artificial intelligence of reason at least at the human level. I am convinced that's true. I am convinced it must be true because as you are going into the final singularity, necessarily ... life can no longer exist, it has to move on another substrate. And, well, that's just human downloads [18].

\section{The Technological Singularity}

Post- and transhumanists collectively identify the mathematician and cyberneticist John von Neumann as the originator of the concept of technological singularity [19]. His detailed obituary was written by his long-time friend and scientific companion Stanisław Ulam in 1958 and he recounts an exchange with von Neumann on the idea of an "ever accelerating progress of technology and changes in the mode of human life, which gives the appearance of approaching some essential singularity in the history of the race beyond which human affairs, as we know them, could not continue." [20:5]

A quarter of a century later, the American mathematician and science fiction author Vernor Vinge explicitly bridges the gap between the cosmological and technological concepts of singularity for the first time, in a one-page article for the technology magazine Omni in 1983:

We will soon create intelligences greater than our own. When this happens, human history will have reached a kind of singularity, an intellectual transition as impenetrable as the knotted space-time at the center of a black hole, and the world will pass far beyond our understanding [21:10].

Over the next years, Vinge applied the singularity merely as a running theme in the background of several of his science fiction novels. At NASA's Vision 21 symposium in 1993 Vinge then confidently announced: "Within thirty years, we will have the technological means to create superhuman intelligence. Shortly after, the human era will be ended." [22] Vinge sketches four ways this technological singularity could appear: first, through computers; second through computer networks that develop consciousness and a superhuman intelligence; third, through human-computer interfaces that make humans super intelligent; or fourth, through the biological improvements of humans. Since the first three possibilities depend heavily on computer hardware, Vinge predicts the arrival of the singularity for the period between 2005 and 2030. He clearly states what his expectations are: "For me, the superhumanity is the essence of the Singularity. Without that we would get a glut of technical riches, never properly absorbed." [23:366].

According to Vinge the singularity will revolutionize all previous structures of human life and will instigate enormous changes in a very short period of time. To date, there is only one corresponding analogy in the history of evolution: "The rise of humankind. We will be in the Post-Human era." [23:367] Everything that will occur after the singularity are completely unknowable. Vinge therefore turns to the concept of the event horizon, as mentioned in his early article from 1983. In astrophysics observations of black holes are not possible beyond this point [23:367].

Vinge as well as most other authors refer to the British mathematician Irving John Good's 1965 essay Speculations Concerning the First Ultraintelligent Machine as the originator of the idea of superintelligence [46]. Good studied mathematics at Cambridge and served at Bletchley Park from 1941, where he was involved in the development of the first electronic computer, Colossus, under the direction of Alan Turing. Later he was professor of statistics at Virginia 
Tech University in the United States. Good introduces his famous essay with a prophetic confession: "The survival of man depends on the early construction of an ultra-intelligent machine." [46:31] This computer, which Good anticipated would have been built by the end of the 20th century, would be far superior to humans in the storage and processing of information:

Let an ultraintelligent machine be defined as a machine that can far surpass all the intellectual activities of any man however clever. Since the design of machines is one of these intellectual activities, an ultraintelligent machine could design even better machines; there would then unquestionably be an "intelligence explosion," and the intelligence of man would be left far behind ... Thus the first ultraintelligent machine is the last invention that man need ever make ... [46:33]

As early as 1962 - at the height of the Cuba crisis - Good expected that future Russian and American ultra-intelligent machines (UIM) could merge into a single world government and guarantee a lasting peace: "Oracles of the world unite!" [47:195]

The American AI researcher Eliezer Yudkowsky first sought to transform the idea of technological singularity into a far-reaching philosophical concept through the formulation of the Singularitarian Principles in 1999. He served as co-founder of the Singularity Institute for Artificial Intelligence (today MIRI), which propelled the singularity debate through its Singularity Summits. Yudkowsky identifies as an atheist, transhumanist and cryonics expert, and pleads in his principles for a sharp distinction between the technological singularity and religious concepts.

The large and often rambling document contains many ambitious statements on "ultra-technology", globalization, the deification of the human being (apotheosis) and solidarity, as well as some minor aspects. Singularitarians are in his view "partisans" who consider technological singularity as superhuman intelligence to be a highly desirable goal to work towards.

The Singularity holds out the possibility of winning the Grand Prize, the true Utopia, the best-of-all-possible-worlds - not just freedom from pain and stress or a sterile round of endless physical pleasures), but the prospect of endless growth for every human being - growth in mind, in intelligence, in strength of personality; life without bound, without end; experiencing everything we've dreamed of experiencing, becoming everything we've ever dreamed of being ... [24]

In the late 1990s, Yudkowsky was one of the few activists to introduce a moment of solidarity into the transhumanist debate. Those who advocate deification must also agree that everyone receives divinity. Those who accept the extermination of humanity by AI must therefore also accept their own extermination. The young Yudkowsky was characterized by a messianic optimism and a belief in the technological solution to all problems of existence: "I'm working to save everyone, heal the planet, solve all the problems of the world." [25].

How does Ray Kurzweil, currently the most influential posthumanist, fit into this debate in comparism to other thinkers? Vernor Vinge legitimizes his own prognosis tautologically: "But if the technological singularity can happen, it will." [22] Frank Tipler justifies technology's future development from the perspective of a cosmological teleology. For Yudkowsky, singularity appears as a given fact. But Ray Kurzweil and Hans Moravec with him choose a different path, one that is apparently oriented towards more verifiable criteria. Both thinkers extrapolate future technological progress by observing previous trends, and Kurzweil alone introduces the concept of singularity in his more recent publications from 2005 [26:95-110], [7:189-252]. It would therefore be prudent to review the development of these forecasts over the past three decades.

If information processing becomes the benchmark for measuring life's perfection, then the past and future will also be interpreted according to this paradigm. Moravec and Kurzweil dedicate large portions of their publications to presenting data on the growth of computers' processing and storage capacities, in addition to detailed questions regarding the possibility of artificial intelligence [2:37-51], [8:14-110]. Both authors attached their hopes for an exponentially accelerated further development and distribution of computers and robots to a quantified law of progress: Moore's Law [2:68], [7:13-25]. The assumption that computer development constantly accelerates can be traced to Intel co-founder Gordon Moore, who in the mid-1960s claimed that the size of an integrated circuit halves every 24 months, in other words, it becomes twice as powerful. This prediction, now known as Moore's Law, implies an indefinite exponential increase in computer performance [7:17-39].

As they aged, Moravec and also Marvin Minsky both became increasingly reserved and also sometimes more skeptical about the imminent realization of artificial intelligence on a human level. In their latest estimates they expect the emergence of a superhuman AI not before the year 2050 [27] - [28]. Unlike the other posthumanist theorists and transhumanist activists, Ray Kurzweil has not become more cautious or restrained in his statements over the last two decades. His three key books The Age of Intelligent Machines (1990) [6], The Age of Spiritual Machines (1999) [7], and The Singularity is Near (2005) [8] offer a dramatic choreography with a steady increase in futuristic statements. As his trilogy concludes, however, he crosses the boundary between technical prophecy and a spiritual philosophy that is more akin to Christianity or New Age beliefs.

As early as 1999, Kurzweil planned what he called the Law of Accelerating Returns. This was intended to replace Moore's Law around 2020 and establish an even higher acceleration rate amongst the future generations of self-designing machines. At this point not only would growth continue exponentially, but in fact the exponent itself would grow exponentially. Therefore - according to Kurzweil's 1999 book - around the year 2023 affordable PCs with the computing power of the human brain would become available, while in 2030 they would contain the mental power of an entire village. By 2029, about $99 \%$ of the thinking power on our planet would be provided by computers. According to Kurzweil, hardly anyone will continue to work in industrial production, agriculture, or the transportation industry [7:17-39] - [8:24-29].

Kurzweil identifies five stages in the history of evolution leading up to the realization of the singularity: 1 . the origin of matter; 2 . the origin of life; 3 . the origin of brains/mind; 4 . the origin of technology; and 5. the fusion of human and machine intelligence. In a sixth phase, superhuman intelligence will begin to colonize the entire universe [8:14-111]. The singularity, which, like the Big Bang, entails creating the entire cosmos anew, marks the absolute climax of this technological prophecy.

Kurzweil only defines this concept briefly: "It's a future period during which the pace of technological change will be so rapid, its impact so deep, that human life will be irreversibly transformed ... " [8:7]. A more precise description is not possible for humans: "So how do we contemplate the Singularity? As with the sun, it's hard to look at directly; it's better to squint at it out of the corner of our eyes." [8:371] Diane Proudfoot points out that this metaphor echoes the doctrine of God's indescribability, which was common in Christian mysticism. Thus Anselm of Canterbury proclaims in the 11th century: "I cannot look directly into [the light in which God dwells], it is too great for me ... it is too bright ... the eye of my soul cannot bear to turn towards it for too long." [29:368]

Kurzweil accentuates the prophetic meaning of his statements with the exact date of the singularity (published in oversized font in the original): 
I set the date for the Singularity - representing a profound and disruptive trans-formation in human capability - as 2045. The nonbiological intelligence created in that year will be one billion times more powerful than all human intelligence today. [8:136]

While Kurzweil's criteria for constituting the realization of the singularity remain rather vague, the promised prospects are boundless. In the opening lines of his book Kurzweil announces that all the magic described in the Harry Potter novels will soon be technologically available [8:4].

The Singularity will allow us to transcend these limitations of our biological bodies and brains. We will gain power over our fates. Our mortality will be in our own hands. We will be able to live as long as we want (a subtly different statement from saying we will live forever). We will fully understand human thinking and will vastly extend and expand its reach. By the end of this century, the nonbiological portion of our intelligence will be trillions of trillions of times more powerful than unaided human intelligence. [8:9]

Kurzweil's book The Singularity is Near includes new reflections on the cosmological significance of earthly events and the ultimate goal of life in the universe. He also adopts Vinge's analogy of the event horizon of black holes: "Just as we find it hard to see beyond the event horizon of a black hole, we also find it difficult to see beyond the event horizon of the historical Singularity." [8:487]

The Russian Internet billionaire Dmitry Itskov's 2045 initiative is also strongly influenced by Kurzweil's futurology. Its research program, launched in 2011, seeks to transfer a human personality into computer memory by the year of singularity. Itskov has named the intermediate stages avatars A-D, in reference to Hindu mythology [12:77-94].

Vernor Vinge and Ray Kurzweil use their understanding of singularity to canonically define its various qualitative elements.

- John von Neumann and Irving Good are the designated authors.

- The singularity entails a radical and rapid change.

- It is a consequence of the evolutionary development of life.

- It is determinate, it will occur in any case.

- It is connected with the development of super-intelligent computer systems.

- Humanity can participate via merging with computers.

- Predictions regarding what happens after the moment of the singularity are not possible.

- The singularity enables human immortality.

- The cosmological and technological concepts of singularity complement one another.

In this context, Frank Tipler's and Eliezer Yudkowsky's designs offer the extreme opposite poles of the techno-prophetic spectrum: Tipler at the Christian end, Yudkowsky at the atheistic - with Vinge and Kurzweil oscillating somewhere in between.

\section{The Cultural Context of the Singularity IDeA}

How can one analyze a temporal concept like the singularity? Is it even a technological fact based on legitimate calculations? Many in the technophile scene have their doubts [48]. Social, psychological and cultural factors play a central role in the proclamation of a coming technological revolution. Nick Bostrom acknowledges that since the 1940s, the prognoses for the realization of artificial intelligence have slid backwards year after year, usually remaining about twenty years away: "Two decades is a sweet spot for prognosticators of radical change: near enough to be attention-grabbing and relevant, yet far enough to make it possible to suppose that a string of breakthroughs, currently only vaguely imaginable, might by then have occurred." [30:4]
At the beginning of the 1990s, MIT professor Pattie Maes noticed that most of her male colleagues were fascinated by the idea of soon being able to upload their brains into computer memory, thus overcoming death. Indeed, they believed that the advent of the first superhuman intelligence would immediately solve the problem of immortality - if only one could survive until this decisive moment. In 1993 Maes spoke about her systematized observations on her colleagues' predictions at the Ars Electronica meeting in Linz (Austria), in a presentation titled "Why Immortality is a Dead Idea". Astonishingly, what she found was that almost all futurists predicted the arrival of immortality within their expected lifetimes. No matter when the predictions were made or how old the actors were, the anticipated salvation would conveniently arrive around age 70 [31:206].

Stuart Armstrong and Kaj Sotala from MIRI have studied the systematics of AI prediction with scientific precision. They analyzed 257 temporal predictions for the arrival of a universal AI (the scope of the question was broader than in Pattie Maes' work, which only focused on predictions of $\mathrm{AI}$ in terms of immortality). Armstrong and Sotala's research found significant uncertainty in predictions about AI. This concerns both prediction methods (including apparent regularities, philosophical arguments, perceived status of the expert) and targets, which ranged from as little as six to more than 75 years. Particularly enlightening was the result that estimates by AI experts had exactly the same variance as those of non-experts (journalists, publicists, or prognosticators from outside the field). In both groups, the majority target a period 15 to 20 years in the future (which confirms Bostrom's impression). Researchers can thusly benefit from their own predictions, receiving research funding or appreciation as renowned experts [32:3-19].

If a revolutionary event is generally expected to occur in about two decades, regardless of when or by whom this prognosis was made, then it becomes important to consider the social dynamics and legitimacy of futurology more closely. What elements make up the singularity as a temporal concept? Firstly, it is justified by laws of progress and acceleration. The singularity also obviously constructs a threshold or boundary - which echoes the idea of the frontier that is so present in American cultural history (including its adaptations in the science fiction genre). As Armstrong and Sotala explain, the status of being a futurologist often serves to legitimize the predictions made. This "charisma of an eschatological prophet", as the sociologist Max Weber would put it, needs to be examined in greater detail.

Not all post- and transhumanists justify the appearance of the singularity - or of AI generally - by revelations or prophecies; they tend to refer to a mathematical theory of progress (e.g. Moore's Law). The assumption that progress is subject to a particular law rather than random chance is often attributed to the 17th-century English philosopher Francis Bacon. However, a general doctrine of progress was actually formulated during the Late Enlightenment through positivism. On the one hand, this philosophy considers scientific and technological developments to be bound by the law of progress. Yet on the other, it also identifies this progress as inherently linked to that of morality and politics. Within this framework, history - like the history of religious salvation before it - was understood as the universal history of all humanity [33:21-22]. On the threshold of the 18th century the French philosophers Fontenelle and Abbe de Saint Pierre first devised the general doctrine of progress. Fontenelle believes that progress was necessary and guaranteed, since following generations would always benefit from the knowledge and mistakes of their predecessors. Abbé de Saint-Pierre, in his vision of social and moral advancement, combined the progress of knowledge with the idea of increasing human happiness [34:98-143].

In 1795 the French philosopher Antoine Marquis de Condorcet published his Esquisse d'un Tableau historique des progrès de l'esprit 
humain. This significantly impacted the English utilitarians, for whom the progress of the human race and the individual was attributed to the law of nature. History - as David Hume and Adam Ferguson agreed - was now to be pursued as a branch of mathematics. It would investigate the causal chain of historical progress, which Turgot and Auguste Comte conceived of mechanistically, in order to better shape the future [35]. At the same time, individual actions became interpreted as part of a larger historical process. A view became widespread that the progress of past ages not only ensured future progress but would also gradually accelerate. As Edward Gibbon predicted in his History of the Decline and Fall of the Roman Empire, it would be "infinitely slow in the beginning, and increasing by degrees with redoubled velocity" [36:169]. According to Francis Bacon, Adam Smith, Immanuel Kant and many other thinkers of that time, the fact of accelerating progress was undeniable for technical and scientific fields. In this way, they deduced the law of progress from both the observation of the past and their hopes for the future.

The inclusion of the utopian perspective as legitimation for the incessant acceleration of progress is a characteristic feature of every such ideology. 200 years before Kurzweil, the assumption that progress would accelerate enormously in the future already served two crucial purposes. Not only were benefits expected to materialize during one's lifetime, but also everyone who was fully committed to the process could count on taking part. A double motivation to believe and support therefore surrounds today's expectations of the singularity just as it did Enlightenment utopias [33:381-383]. The idea of everincreasing acceleration is also due to another cultural source. The German scholar of religion Ernst Benz points out that such incessant acceleration was a characteristic of Christian salvation history. The discovery and Christianization of America was also shaped by these eschatological expectations. Columbus - convinced of the approaching end of the world - saw India (i.e. America) as Satan's last empire to be proselytized. According to Benz, the fundamental idea of accelerating progress is contextualized by the subjective expectation of salvation - that ultimate Christian goal. This is further nourished by New Testament reports and the visions recorded in the Book of Revelation or by the apostle Stephen. This longing for acceleration is particularly associated with the American theory of progress, which has often understood the unfolding history as part of God's plan for the coming of the promised land [37:18-21].

In addition to this idea of increasing acceleration, another crucial allusion to American cultural history is found in the understanding of the singularity as the last frontier. Since Puritans settled Massachusetts in the 17th century, the frontier has marked the border of the civilized and moral world against the wilderness, represented by the disordered chaos of the indigenous tribes of North America. The Christiancolonial sense of missionary purpose was further reinforced in the 1840s, when expansionist tendencies in American politics (particularly the annexation of Texas) were merged with the project of spreading freedom and democracy. They believed it be the manifest destiny of God's chosen American people to sow progress, civilization and freedom in the wild and untamed vastness of the continent. [38:69-77]

After the geographical frontier disintegrated with the settlement of the West and the extermination of most indigenous peoples, the frontier's metaphorical significance grew in other areas of society, especially science. Francis Bacon had already portrayed the researcher as a pioneer who ventured into undiscovered worlds. However, it was Vannevar Bush, the scientific advisor to President Franklin D. Roosevelt, who immortalized the metaphor for American academia in 1945 with his report Science - the Endless Frontier. In this document, Bush proposes guidelines for promoting science in the United States, which led, among other things, to the establishment of the National Science Foundation.
It has been basic United States policy that Government should foster the opening of new frontiers. It opened the seas to clipper ships and furnished land for pioneers. Although these frontiers have more or less disappeared, the frontier of science remains. It is in keeping with the American tradition - one which has made the United States great - that new frontiers shall be made accessible for development by all American citizens. [39:46]

From John F. Kennedy to George W. Bush and Barack Obama, the metaphor of the intellectual frontier has continued to play an important role in American scientific policy [39:29-155].

As conceptualized by Vinge, Yudkowsky and Kurzweil, the singularity is based on this important metaphor of the endless frontier. The singularity in the sense of an event horizon of black holes remains impenetrable and insurmountable for humans. But for artificial intelligence, the singularity would be the beginning of an unlimited expansion into the universe, in which humans are also allowed to participate.

As already indicated, this perception of singularity as the last boundary to be overcome has been popularized by numerous adaptations in science fiction stories and films. This genre establishes the connection between the spatial and the scientific metaphors i.e. human civilization finally surpasses the last frontier of human knowledge as it moves into space. One particular catalyst for such ideas was the scientific work of the Princeton physicist Gerard O'Neill (1927-1992), who from the 1970s onwards presented numerous technical designs for colonizing space, the High Frontier [40:168-208].

In the fifth Star Trek movie, The Final Frontier (1989), Captain Kirk is forced to overcome the "Great Barrier" in the center of the Milky Way on his spaceship, in order to seek God on a mythical planet. The first two Star Trek television series (1966-1969, 1987-1994) always prefaced their opening credits with the magic words: "Space, the final frontier." Less fantastically, in The Black Hole (1979) Maximilian Schell, playing the brilliant but unscrupulous scientist Dr. Hans Reinhardt, tried to convince a stranded spaceship crew that the ultimate truth, God, and eternal life in a world beyond physical laws waiting for them on the other side of a black hole. The scientist then transforms the recalcitrant members of his own crew into mindless cyborgs. At the end of the film, the surviving heroes actually fly through a Danteinspired, hellish inferno and then glide behind an angel into a paradise flooded with light. In the 20th century Western heroes thus seamlessly transform into space heroes. The overcoming of the final frontier - the singularity of black holes - becomes the heroic enterprise of white men, whether these come equipped with heterogeneous accents like a fist-swinging macho (James Tiberius Kirk) or as possessed geniuses (Max Reinhardt) [40:139-167].

There is also no question that the temporal aspect of the singularity is influenced by the Christian end of days. The overcoming of old age, illness and death corresponds to the Christian expectation of salvation (especially in Tipler's vision of a resurrection of the dead). However, the essential analogy to the Christian apocalypse remains ambiguous: the singularity is neither the result of a continuous and positive development of progress nor of total annihilation. Like the Christian history of salvation, the concept connects the downfall of human beings with the certainty of a post-singular promise: death followed by resurrection.

Christian and singularity prophecies share another important structural feature: that signs reveal the imminence of this end. The Revelation of John lists many apocalyptic elements (prophecies, destructions, sacrifices, testimonies) that occur before the final battle against Satan and the Last Judgment (Rev 4-20). In his three futuristic books, Kurzweil in particular develops an increasingly precise description of milestones that will precede the singularity, including an evaluation of his own earlier predictions.

Unlike in Vinge and Kurzweil's version of the singularity, Christian writings do in fact provide a precise description of the post-apocalyptic 
period: The New Jerusalem is described in great detail (Rev 21-22). In the Christian and Jewish traditions, salvation is dependent on God's judgment of one's moral conduct. According to all posthumanist authors, the singularity makes immortality available to every living human being. This idea of universal salvation for all human beings is only found explicitly amidst the Unitarian Universalists, who in their 1803 Winchester Profession proclaimed that the one Holy Spirit of Grace " ... will finally restore the whole family of mankind to holiness and happiness." [41] The fact that Kurzweil grew up a Unitarian should not be overestimated at this point, as other advocates of singularity reach the same conclusion.

One final relevant aspect for this analysis lies in the role of the heralds of the singularity. Here Ray Kurzweil stands out, both in terms of his claims and the colorfulness of his autobiographical selfrepresentation. Although he can reflect on a number of inventions and awards accomplished during the 1970s and 1980s, he has not yet been able to utilize the Internet and digitalization to achieve any technological breakthroughs. Compared to today's Internet entrepreneurs, he is only a lightweight with his estimated assets of $\$ 27$ million. Naturally, the question then arises as to why Kurzweil in particular is called upon to praise singularity and system-changing technologies when he himself apparently has been alrgely unable to benefit at all from those trends. For him, the construction of a charismatic genius was even more important.

While in kindergarten Kurzweil was already aware of his own destiny: "At the age of five, I had the idea that I would become an inventor. I had the notion that inventions could change the world." [8:1] He built his first robots at the age of eight. He believes not only that he foresaw technological innovations, but in his 1990 book The Age of Spiritual Machines he also claims to have predicted the demise of the Soviet Union (1990/91) due to decentralized communication networks [6:446447]. The documentary film Transcendent Man. The Life and Ideas of Ray Kurzweil from 2009 is a brilliant example of modern hagiography: a "legend of saints". In it, Kurzweil is accompanied by the film crew on his worldwide lectures. His followers, such as actor William Shatner, singer Stevie Wonder or former Secretary of State Colin Powell, praise him hyperbolically on camera. One immediately notices Kurzweil's trauma at losing his father, as well as his obsession with reaching the age of singularity through taking 150 vitamin pills daily. Apart from the mantra that the singularity is near and will change everything, the film does not contain much substance, and actually offers no indepth discussion of the concept [12:100]. The films The Singularity (2012) by Doug Wolens and the film The Singularity is Near (2010), produced by Kurzweil himself, did not focus on the figure of Kurzweil. However, they were able to further popularize this futuristic scenario. The continual acceleration that Kurzweil promotes in his three futurological monographs offers a recognizable parallel to religious prophecy. This phenomenon is uncannily familiar in the history of religion, especially regarding the lack of fulfilled predictions. This feature is particularly striking in Kurzweil's work, since all other postand transhumanist thinkers of recent decades relativize or tone down their predictions, or else broaden their temporal horizons. One might even be tempted to suggest a new Law of Increasing Disappointment, whereby the only things growing exponentially in transhumanism are the predictions themselves.

As a prophetic figure, Kurzweil also claims a special position: Vannevar Bush declared the endless frontier of the sciences in 1945. Kurzweil proclaims the end of this period of searching for knowledge will occur precisely one century later in the year 2045 . He thus situates himself as the last prophet of the end times, the seal of the prophets. No further advances in prophecy could surpass Kurzweil's visions: when the singularity arrives humankind's time will be finished, and the fate of the universe will be decided.
IV. Conclusion

In the movies Terminator (1984) and the Matrix trilogy (1999-2003), a powerful artificial intelligence seeks to exterminate or enslave the (last) humans. Similarly, in marked contrast to the naive futurologies of Kurzweil and the transhumanists, postsingularity science fiction predominantly follows the tradition of dystopian cyberpunk literature [42:124-125]. Elaine Graham notes that more recent science fiction is increasingly blatant in dissolving the boundary between religion and science. The secular and the sacred; the human being and God; faith and knowledge; these all appear increasingly less as polar opposites, but rather now merge and blur in a post-secular era [43:362]. Dystopian visions no longer propagate the overcoming of a religious superstition by a rationalist techno-culture, but rather now celebrate the fusion of these two spheres.

For example, in Rudy Rucker's novel Postsingular of 2007 [44], a Christian fundamentalist US president seeks to transform the entire Earth into a virtual earth (Vearth) with the help of a computer scientist using nano-robots. He sees this transformation as the realization of biblical prophecy via restoration of the Garden of Eden, where suffering, war, and death are banished, and life is completely coordinated. Rucker reveals that this desire stems from trauma experienced by the computer scientist during his youth, when he lost his friend in an accident. In Postsingular, the interests of Christian and cybernetic fundamentalism overlap in their hatred of both women and creation in general [44] - [42:40-45].

It seems obvious that the prophecy of singularity is strongly influenced by cultural and religious ideas. The assumption of laws of progress, as well as the steady acceleration of progress claiming universal validity for the entire history of humankind, can all be traced back to an Enlightenment striving for perfection. But what is new in the singularity is Vinge and Kurzweil's idea introduced of an absolute and impenetrable limit to this progress: the singularity as the last frontier. The term repeats semantics from the physics of black holes, as well as their popularized representations in literature and film. Even more astonishing is that the concept of singularity allows a religious teleology to creep into post- and transhumanism, which 15 years ago was dismissed as exotic. This occurs first and foremost structurally, as the entire history of earthly life heads towards a moment of salvation. In concrete terms this happened when Ray Kurzweil bluntly adopted Frank Tipler's notion of the complete colonization of the universe, culminating in the realization of God [19].

Actually, the British science fiction author Charles Stross had already anticipated the conclusion of my analyses in his short story Accelerando (2005) with a few words. After extensive debates about the nature of the singularity, one of the two characters sums up laconically:

"Is not happening yet," contributes Boris. "Singularity implies infinite rate of change achieved momentarily. Future not amenable thereafter to prediction by presingularity beings, right? So has not happened ... Singularity is load of religious junk. Christian mystic rapture recycled for atheist nerds." [45:184]

\section{ACKNOWLEDGMENT}

I would like to thank Ralf Hoffmann, Ali Jones and Paul Knight for their kind support and advice.

REFERENCES

[1] Godling's Glossary 1998. Quoted by Anders Sandberg. Accessed: 01/15/2021 (Online). Available: aleph.se/Trans/Global/Singularity/index.html.

[2] H. Moravec, Mind Children. The Future of Robot and Human Intelligence, Harvard: Harvard UP, 1988. 
[3] F. J. Tipler, The Physics of Immortality. Modern Cosmology, God and the Ressurection of the Dead, New York: Anchor, 1995.

[4] M. L. Minsky, Computation. Finite and Infinite Machines, Prentice Hall: Englewood Cliffs, 1967.

[5] C. Keller, Buildung Bodies. Der Mensch im biotechnischen Zeitalter. Reportagen und Essays, Zürich: Limmat, 2003.

[6] R. Kurzweil, The Age of Intelligent Machines, Cambridge: MIT Press, 1990.

[7] R. Kurzweil, The Age of Spiritual Machines. When Computers Exceed Human Intelligence, New York: Viking Press, 1999.

[8] R. Kurzweil, The Singularity is Near. When Humans transcend Biology, New York: Penguin Books, 2005.

[9] R. Kurzweil, T. Grossman, Fantastic Voyage. Live Long Enough to Live Forever, New York: Rodale Books, 2004.

[10] R. Kurzweil, T. Grossman, Transcend: Nine Steps to Living Well Forever, New York: Rodale Books, 2010.

[11] B. Ptolemy, Transcendent Man, USA 2009 (Movie).

[12] T. Wagner, Robokratie. Google, das Silicon Valley und der Mensch als Auslaufmodell, Köln: PapyRossa Verlag, 2015.

[13] S. Bringsjord, A. Bringsjord, P. Bello, "Belief in the Singularity is Fideistic," in Singularity Hypothesis. A Scientific and Philosophical Assessment, A. H. Eden et al. Ed. Berlin: Springer, 2012, pp. 394-408.

[14] R. Heil, "Transhumanismus, Nanotechnologie und der Traum von Unsterblichkeit," in Visionen der Nanotechnologie, A. Ferrari, S. Gammel Eds. Heidelberg: Akademische Verlagsgesellschaft, 2010, pp. 25-49.

[15] S. Hawking, R. Penrose, "The Singularities of Gravitational Collapse and Cosmology," in Proceedings of the Royal Society, vol. 314, pp. 529-548, 1970.

[16] J. D. Barrow, F. J. Tipler, The Anthropic Cosmological Principle, Oxford / New York: Oxford University Press, 1986.

[17] F. J. Tipler, The Physics of Christianity, New York: Penguin Books, 2007.

[18] F. J. Tipler, "The Laws of Physics Say The Singularity is Inevitable!" Interview (Video) with Socrates / Nikola Danaylov of the SingularityWeblog 10/29/2013. Accessed: 01/15/2021 (Online). Available: https://www.singularityweblog.com/frank-j-tipler-the-singularity-isinevitable

[19] O. Krüger, Virtual Immortality. God, Evolution and the Singularity in Postand Transhumanism. New York: Columbia University Press, 2021.

[20] S. Ulam, "John von Neumann 1903-1957," in Bulletin of the American Mathematical Society, vol. 64, pp. 1-49, 1958.

[21] V. Vinge, "First Word," in Omni, January, p. 10, 1983.

[22] V. Vinge, "The Coming Technological Singularity. How to Survive in the Post-Human Era." 1993. Accessed: 01/15/2021 (Online). Available: http:// mindstalk.net/vinge/vinge-sing.html.

[23] V. Vinge, "Technological Singularity," in The Transhumanist Reader, M. More, N. Vita-More Eds. Chichester: Wiley-Blackwell, 2013, pp. 365-375.

[24] E. S. Yudkowsky, "Singularitarian Principles. Version 1.0.2. Extended Edition." 2000. Accessed 01/15/2021 (Online). Available: https://web. archive.org/web/20070613190005/http://yudkowsky.net/sing/principles. ext.html\#preface.

[25] E. S. Yudkowsky, "Singularitarian Principles. Version 1.0.2. Extended Edition." 2000. Accessed 01/15/2021 (Online). Available: http:// yudkowsky.net/obsolete/principles.html.

[26] H. Moravec, Robot. Mere Machine to Transcendent Mind, Oxford / New York: Oxford University Press, 1999.

[27] M. L. Minsky, "Marvin Minsky on Singularity." Interview with Socrates / Nikola Danaylov of the SingularityWeblog, 07/12/2013. Accessed 01/15/2021 (Online). Available: https://www.youtube.com/ watch? $=3$ PdxQbOvAlI.

[28] H. Moravec, "Rise of the Robots - The Future of Artificial Intelligence," in Scientific American, 03/23/2009. Accessed 01/15/2021 (Online). Available: https://www.scientificamerican.com/article/ rise-of-the-robots.

[29] D. Proudfoot, "Software Immortals: Science or Faith?" in Singularity Hypothesis. A Scientific and Philosophical Assessment, A. H. Eden et al. Eds. Berlin: Springer, 2012, pp. 367-394.

[30] N. Bostrom, Superintelligence. Paths, Dangers, Strategies. Oxford: Oxford University Press, 2014.

[31] R. Brooks, Flesh and Machines. How Robots will Change us, New York: Vintage, 2002.

[32] S. Armstrong, K. Sotala, "How We're Predicting AI - or Failing To." 2012. Accessed 01/15/2021 (Online). Available: https://intelligence.org/files/ PredictingAI.pdf.
[33] D. Spadafora, The Idea of Progress in Eighteenth-Century Britain, New Haven: Yale University Press, 1990.

[34] J. B. Bury, The Idea of Progress. An Inquiry into Its Origin and Growth. New York: Dover Publications, 1955.

[35] J.-A.-N. Marquis de Condorcet, Esquisse d'un Tableau historique des progrès de l'esprit humain, Paris: Vrin, 1970.

[36] E. Gibbon, The History of the Decline and the Fall of the Roman Empire, vol. 4, London: Methuen, 1925.

[37] E. Benz, "Akzeleration der Zeit als geschichtliches und heilsgeschichtliches Problem," in Abhandlungen der Geistes- und Sozialwissenschaftlichen Klasse der Akademie der Wissenschaften und der Literatur, vol. 2, pp. 1-53, 1977.

[38] J. D. Torr, The American Frontier, San Diego: Greenhaven Press, 2002.

[39] L. Ceccarelli, On the Frontier of Science. An American Rhetoric of Exploration and Exploitation, East Lansing: Michigan State University Press, 2013.

[40] M. W. Kapell, Exploring the Next Frontier. Vietnam, NASA, Star Trek and Utopia in 1960s und 1970s American Myth and History, New York: Routledge, 2016.

[41] Unitarian Winchester Profession, 1803/1899. Accessed 01/15/2021 (Online). Available: https://uudb.org/articles/winchester.html.

[42] J. Raulerson, Singularities. Technoculture, Transhumanism, and Science Fiction in the Twenty-first Century, Liverpool: Liverpool University Press, 2013.

[43] E. L. Graham, "The Final Frontier? Religion and Posthumanism in Film and Television," in The Palgrave Handbook of Posthumanism in Film and Television, M. Hauskeller, T. D. Philbeck, C. Carbonell Eds. New York: Palgrave, 2015, pp. 361-370.

[44] R. Rucker, Postsingular. New York: Tor Books, 2007.

[45] C. Stross, Accelerando. London: Orbit, 2005.

[46] I. J. Good, "Speculations Concerning the First Ultraintelligent Machine," in Advances in Computers, vol. 6, pp. 31-88, 1965.

[47] I. J. Good, "The Social Implications of Artificial Intelligence," in The Scientist Speculates: An Anthology of Partly-Baked Ideas, I. J. Good Ed. London: Basic Books, 1962, pp. 192-198.

[48] B. Cantwell Smith, The Promise of Artificial Intelligence. Reckoning and Judgement. Cambridge: MIT Press 2019.

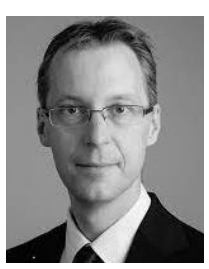

\section{Oliver Krüger}

Oliver Krüger (*1973) studied Sociology, Classical Archeology and the Religious Studies at the University of Bonn (Germany) from 1994-1999, graduated with a Master in Sociology. In 2003 he received his Ph.D. in Religious Studies from Bonn University. From 2002-2005 he was a research fellow and lecturer at the collaborative research center Dynamics of Rituals at the University of Heidelberg. From 2005 to 2007 he was a Visiting Fellow and Visiting Lecturer at the Center for the Study of Religion at Princeton University. In 2007 he became Professor for Religious Studies Fribourg University (Switzerland). He served as President of the Swiss Society for the Study of Religion from 2011-2014 and in 2012/13 he was fellow at the Center for Advanced Studies Morphomata (University of Cologne). Major publications are: Virtual Immortality. God, Evolution and the Singularity in Post- and Transhumanism. New York: Columbia University Press 2021; Die mediale Religion, transcript: Bielefeld: transcript 2012; "Gaia, God, and the Internet - revisited. The History of Evolution and the Utopia of Community in Media Society," in: Online - Heidelberg Journal for Religions on the Internet, vol. 8, 2015. 